\title{
Enhanced INL Power Grid Test Bed Infrastructure - Phase I
}

\author{
Carol Reid
}

Shawn West

Scott McBride

June 2014

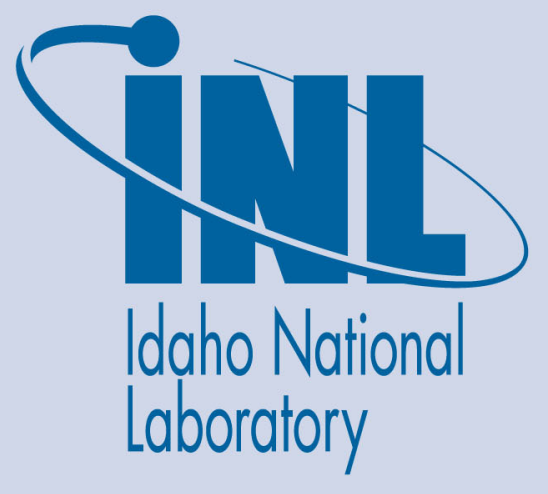

The INL is a U.S. Department of Energy National Laboratory operated by Battelle Energy Alliance 


\section{DISCLAIMER}

This information was prepared as an account of work sponsored by an agency of the U.S. Government. Neither the U.S. Government nor any agency thereof, nor any of their employees, makes any warranty, expressed or implied, or assumes any legal liability or responsibility for the accuracy, completeness, or usefulness, of any information, apparatus, product, or process disclosed, or represents that its use would not infringe privately owned rights. References herein to any specific commercial product, process, or service by trade name, trade mark, manufacturer, or otherwise, does not necessarily constitute or imply its endorsement, recommendation, or favoring by the U.S. Government or any agency thereof. The views and opinions of authors expressed herein do not necessarily state or reflect those of the U.S. Government or any agency thereof. 
INL/EXT-14-32364

Revision 0

\title{
Enhanced INL Power Grid Test Bed Infrastructure - Phase I
}

\author{
Carol Reid \\ Shawn West \\ Scott McBride
}

June 2014

Idaho National Laboratory Idaho Falls, Idaho 83415

http://www.inl.gov

\author{
Prepared for the \\ U.S. Department of Energy \\ Office of Electricity Delivery and Energy Reliability (DOE-OE) \\ Under DOE Idaho Operations Office \\ Contract DE-AC07-05ID14517
}




\section{CONTENTS}

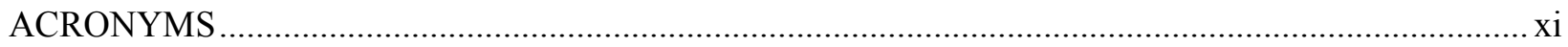

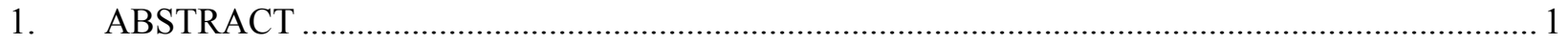

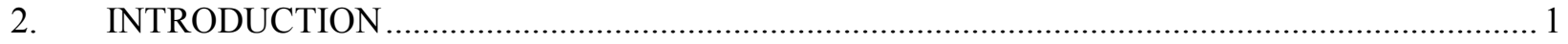

2.1 Existing INL CITRC Test Bed Infrastructure/Capability ................................................ 2

2.2 Power Grid Test Bed Enhancement Project - Phase I ...................................................... 4

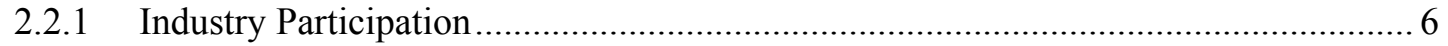

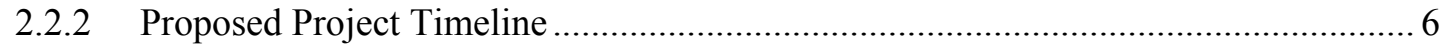

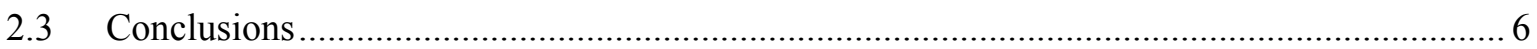

\section{FIGURES}

Figure 1. INL Reservation with 138kV Transmission Loop................................................................ 2

Figure 2. Existing CITRC Substation and Distribution System. ........................................................ 3

Figure 3. Phase I Substation and Distribution System Enhancement. ..................................................... 5

\section{TABLES}

Table 1. Select MGI-DT Prototypical feeders which could be represented by existing INL distribution feeders.

Table 2. Additional MGI-DT Prototypical feeders which could be represented by the enhanced INL power grid test bed distribution feeder network. 4 


\section{ACRONYMS}

INL Idaho National Laboratory

DOE Department of Energy

DOE-OE DOE Office of Electricity Delivery and Energy Reliability

FY fiscal year

CITRC Critical Infrastructure Test Range Complex

PNNL Pacific Northwest National Laboratory

APPA American Public Power Association

MGI-DT Modern Grid Initiative Distribution Taxonomy

EPRI Electric Power Research Institute 


\section{Enhanced INL Power Grid Test Bed Infrastructure - Phase I}

\section{ABSTRACT}

Idaho National Laboratory (INL), a Department of Energy (DOE) laboratory, owns, operates, and maintains transmission and distribution power grid infrastructure to support the INL multi-program mission. Sections of this power infrastructure, known as the INL Power Grid Test Bed, have been and are being used by government and industry to develop, demonstrate, and validate technologies for the modern grid, including smart grid, on a full-scale utility test bed.

INL's power grid includes 61 miles of $140-\mathrm{MW}, 138-\mathrm{kV}$ rated electrical power transmission supplying seven main substations, each feeding a separate facility complex (or 'city') within the INL's 890 -square mile Site. This power grid is fed by three commercial utilities into the INL's main control substation, but is operated independently from the commercial utility through its primary substation and command and control center.

Within the INL complex, one of the seven complexes, the Critical Infrastructure Test Range Complex (CITRC), has been designated as the INL complex for supporting critical infrastructure research and testing. This complex includes its own substation and $13.8 \mathrm{kV}$ distribution network, all configurable and controlled by the INL research and development programs. Through investment partnership with the DOE Office of Electricity Delivery and Energy Reliability (DOE-OE), INL is enhancing its existing distribution infrastructure to expand the types of testing that can be conducted and increase flexibility for testing configurations. The enhancement of the INL Power Grid Test Bed will enable development and full-scale testing of smart-grid-related technologies and smart devices including testing interoperability, operational performance, reliability, and resiliency contribution at multiple distribution voltage classes, specifically $15 \mathrm{kV}, 25 \mathrm{kV}$, and $35 \mathrm{kV}$. The expected time-frame for completion of the Phase I portion of the enhancement would be $4^{\text {th }}$ quarter fiscal year (FY) 2015.

\section{INTRODUCTION}

The performance of the traditional national grid power distribution system determines greater than $90 \%$ of the reliability of service to customers. The high-voltage transmission and generation system determines the remainder ${ }^{\mathrm{a}, \mathrm{b}}$. If performance and reliability of the overall power delivery system is to be improved during smart grid transition, the majority of the improvements will be affected through smart-grid implementation associated with the distribution system.

To support development, performance validation testing, and implementation of smart-grid for the nation's distribution systems, DOE-OE is working with INL to expand INL's CITRC Electric Power Grid Test Bed distribution infrastructure. The phased expansion would enable full-scale testing of new smart grid distribution systems, technologies, and components optimized to represent a majority of the national grid voltage class distribution systems. During Phase I of this multi-phase effort, enhancements to the CITRC substation and associated distribution grid will be optimized to represent the national grid major distribution system voltage classes $15-, 25-$, and $35-\mathrm{kV}^{2, \mathrm{c}, \mathrm{d}}$.

\footnotetext{
a. Brown, Richard, "Electric Power Distribution Reliability," Marcel Dekker Inc., New York, NY, 2002, pp. 1-15

b. Short, T. A., Electric Power Distribution Handbook, 2004, ISBN 0-8493-1791-6, sponsored by the Electric Power Research Institute (EPRI)

c. Pacific Northwest National Laboratory (PNNL) "Modern Grid Initiative Distribution Taxonomy Final Report," PNNL-18035, November 2008

d. American Public Power Association (APPA), “APPA Evaluation of Data Submitted in APPS's 2013 Distribution System Reliability \& Operations Survey,” March 2014.
} 
Specific enhancements envisioned for Phase I include:

- Substation configuration to supply multiple voltages to the distribution lines, specifically $15 / 25 / 35 \mathrm{kV}$ class

- Distribution lines designed to operate at multiple voltages

- Distribution lines configured to operate in radial configuration or interconnected to operate in a mesh-configuration

- Dedicated substation control for the multi-voltage distribution system

- Interface points at line ends and midpoints which provide equipment power (high and low voltage), instrumentation power, and communications interconnection points

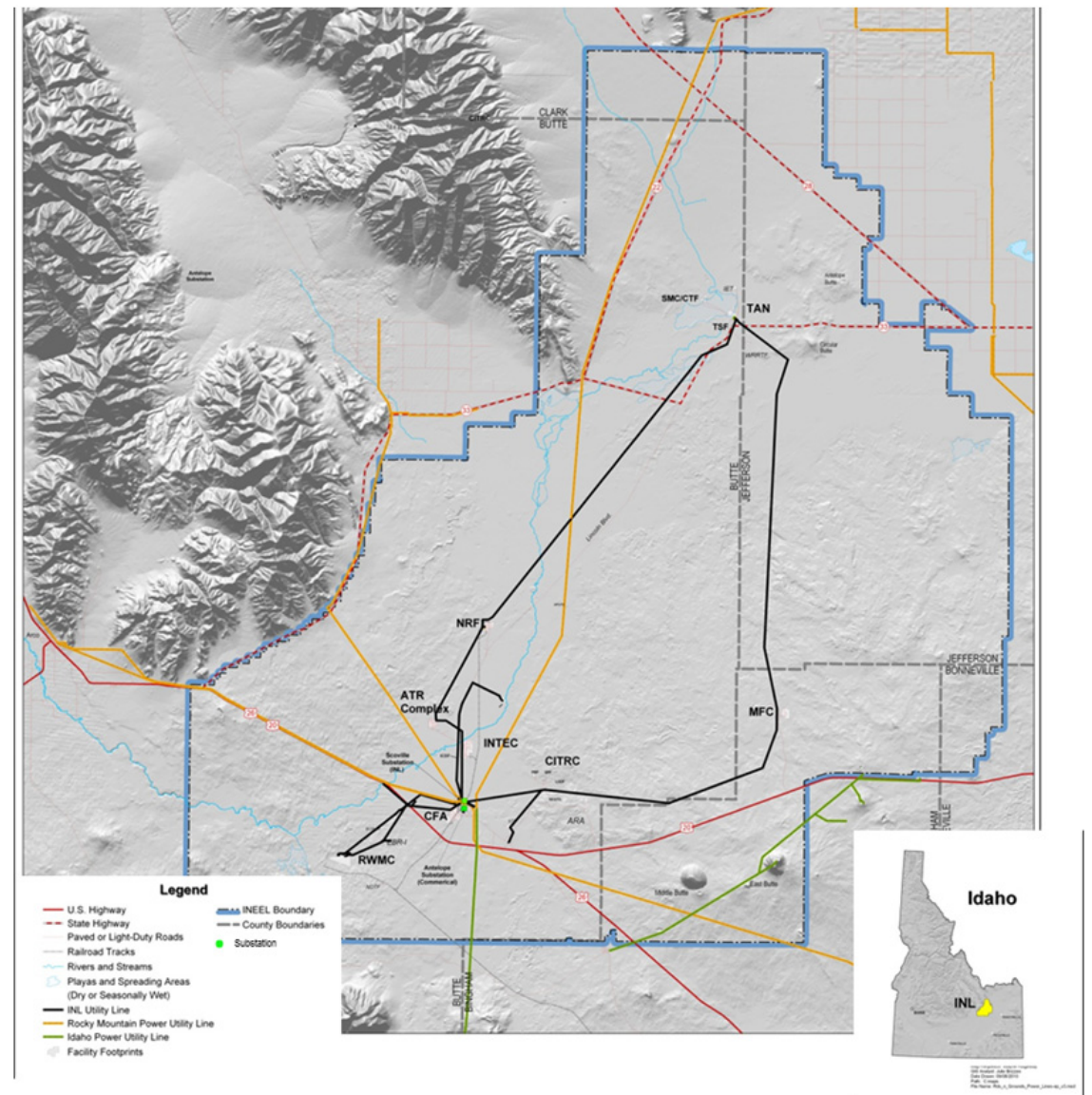

Figure 1. INL Reservation with $138 \mathrm{kV}$ Transmission Loop. for test and measurement equipment.

Note that the extent and type of specific enhancements may change as a result of the trade-off studies, budget constraints, and performance optimization identified during the conceptual design process. The future phases of development will be defined as part of the trade-off studies performed during the Phase I conceptual design process.

\subsection{Existing INL CITRC Test Bed Infrastructure/Capability}

In its present configuration, INL's distribution grid operates at nominally $13.8-\mathrm{kV}$ (see Figure 1) and is available to support smart-grid-related research, testing, and demonstration. These distribution feeders include six radial lines, four that are approximately 1/2-mile long, one line approximately 4-miles long, and one line approximately 3-miles long (see Figure 2). Typically these lines are used to support single, individual tests. One distribution circuit has single mode fiber optic communications capability. 


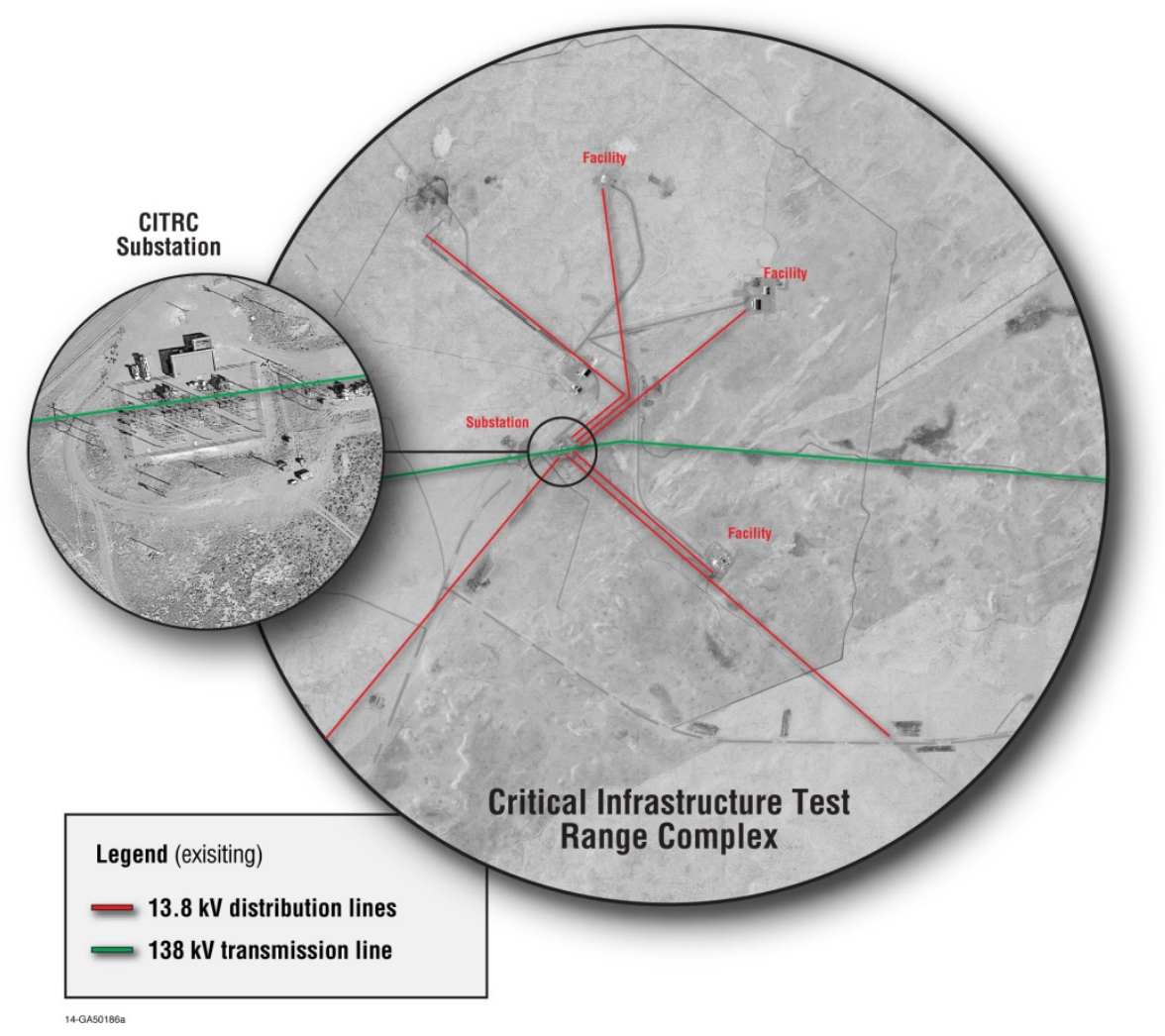

Figure 2. Existing CITRC substation and distribution System.

Review of the characteristics of the 24 prototypical feeders identified in the MGI-DT report identified the prototypical feeders that INL's power grid test bed could most generally simulate (see Table 1).

Table 1. Select MGI-DT prototypical feeders that could be represented by existing INL distribution feeders.

\begin{tabular}{|c|c|c|c|c|l|}
\hline Feeder ID & $\begin{array}{c}\text { Voltage } \\
(\mathrm{kV})\end{array}$ & $\begin{array}{c}\text { Load } \\
(\mathrm{kW})\end{array}$ & $\begin{array}{c}\text { Percent } \\
\text { Overhead }\end{array}$ & $\begin{array}{c}\text { Percent } \\
\text { Underground }\end{array}$ & \multicolumn{1}{|c|}{ Comments } \\
\hline R1-12.47-1 & 12.5 & 7,150 & 60 & 40 & $\begin{array}{l}\text { Moderately populated suburban and } \\
\text { rural area }\end{array}$ \\
\hline R1-12.47-2 & 12.47 & 2,830 & 70 & 30 & $\begin{array}{l}\text { Moderately populated suburban and } \\
\text { lightly populated rural area }\end{array}$ \\
\hline R1-12.47-3 & 12.47 & 1,350 & 85 & 15 & Moderately populated urban area \\
\hline R2-12.47-2 & 12.47 & 6,100 & 80 & 20 & Moderately populated suburban area \\
\hline R3-12.47-3 & 12.47 & 7,800 & 75 & 25 & Heavily populated suburban area \\
\hline R4-12.47-2 & 12.47 & 2,200 & 92 & 8 & Lightly populated suburban area \\
\hline R5-12.47-1 & 13.8 & 9,400 & 95 & 5 & Heavily populated suburban area \\
\hline R5-12.47-3 & 13.8 & 9,200 & 92 & 8 & Moderately populated rural area \\
\hline R5-25.00-1 & 22.9 & 12,000 & 35 & 65 & Heavily populated suburban area \\
\hline GC-12.47-1 & 12.47 & 5,200 & 100 & & Large Industrial Load \\
\hline
\end{tabular}


From a voltage class perspective, the current INL Power Grid Test Bed distribution assets, which includes CITRC, could be leveraged to simulate 10 out of the 24 , or $42 \%$, of the Modern Grid Initiative Distribution Taxonomy (MGI-DT) prototypical feeder voltage classes as presented in the November 2008 Pacific Northwest National Laboratory (PNNL) final report.

\subsection{Power Grid Test Bed Enhancement Project - Phase I}

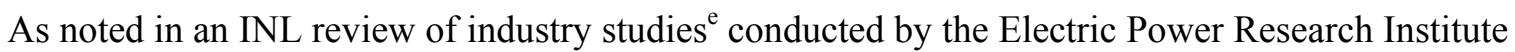
(EPRI), PNNL, and APPA, the predominant evaluated feeder characteristics were the actual feeder voltage and the feeder voltage class (classes group similar operating voltages for simplification of manufacture and selling of power equipment). The proposed power grid test bed enhancements would enable INL to simulate voltage classes of an additional five of the MGI-DT prototypical distribution feeders for a total of 15 out of the 24 identified, or $62 \%$. These additional feeders would include both $25-\mathrm{kV}$ class and $35-\mathrm{kV}$ class feeders.

The proposed power grid test bed enhancements will significantly enhance the power distribution systems available at INL to conduct industry scale testing. Specifically, they will allow INL to test and operate at higher distribution voltages which is the way the industry is headed due to operational efficiencies associated with higher voltages. The proposed enhancements will allow INL to simulate operational conditions associated with the following additional MGI-DT prototypical feeders (see Table 2).

Table 2. Additional MGI-DT prototypical feeders that could be represented by the enhanced INL Power Grid Test Bed distribution feeder network.

\begin{tabular}{|c|c|c|c|c|l|}
\hline Feeder ID & $\begin{array}{c}\text { Voltage } \\
(\mathrm{kV})\end{array}$ & $\begin{array}{c}\text { Load } \\
(\mathrm{kW})\end{array}$ & $\begin{array}{c}\text { Percent } \\
\text { Overhead }\end{array}$ & $\begin{array}{c}\text { Percent } \\
\text { Underground }\end{array}$ & \multicolumn{1}{c|}{ Comments } \\
\hline R1-25.00-1 & 24.9 & 2,100 & 60 & 40 & Lightly populated rural area \\
\hline R2-25.00-1 & 24.9 & 17,000 & 60 & 40 & Moderately populated suburban area \\
\hline R2-35.00-1 & 34.5 & 8,900 & 90 & 10 & Lightly populated rural area \\
\hline R4-25.00-1 & 24.9 & 950 & 88 & 12 & Lightly populated rural area \\
\hline R5-35.00-1 & 34.5 & 12,000 & 10 & 90 & $\begin{array}{l}\text { Moderately populated suburban area } \\
\text { with a lightly populated urban area }\end{array}$ \\
\hline
\end{tabular}

Thus, the enhanced INL Smart Grid Test Bed will enable development and system scale testing of smart-grid-related technologies and smart devices for interoperability, operational performance, reliability, and resiliency at distribution scale at multiple distribution voltage classes, specifically $15-\mathrm{kV}$, $25-\mathrm{kV}$, and 35-kV (see Figure 3).

The equipment envisioned to support the Phase I construction includes, but is not limited to the following:

- New multi-tap pad-mounted transformer and associated switchgear to support distribution operations in the voltage classes from $15-\mathrm{kV}$ to $35-\mathrm{kV}$ will be installed near the CITRC substation.

- Prefabricated walk-in style centralized smart-grid command center-an environmentally controlled pre-fabricated type shelter will be installed at the CITRC substation and designated as the centralized smart-grid test-bed command center. The command center will be constructed and equipped to manage and monitor local distribution configurations, test-bed operations, and provide a centralized hub for all test bed local and external data communications. The centralized operations will include

\footnotetext{
e McBride, S., "Feeder Taxonomy Response,” May 20, 2014
} 
provisions for coordinating test operations using the existing CITRC substation transformers, distribution switchgear, and related subsystems with INL power dispatch operations.

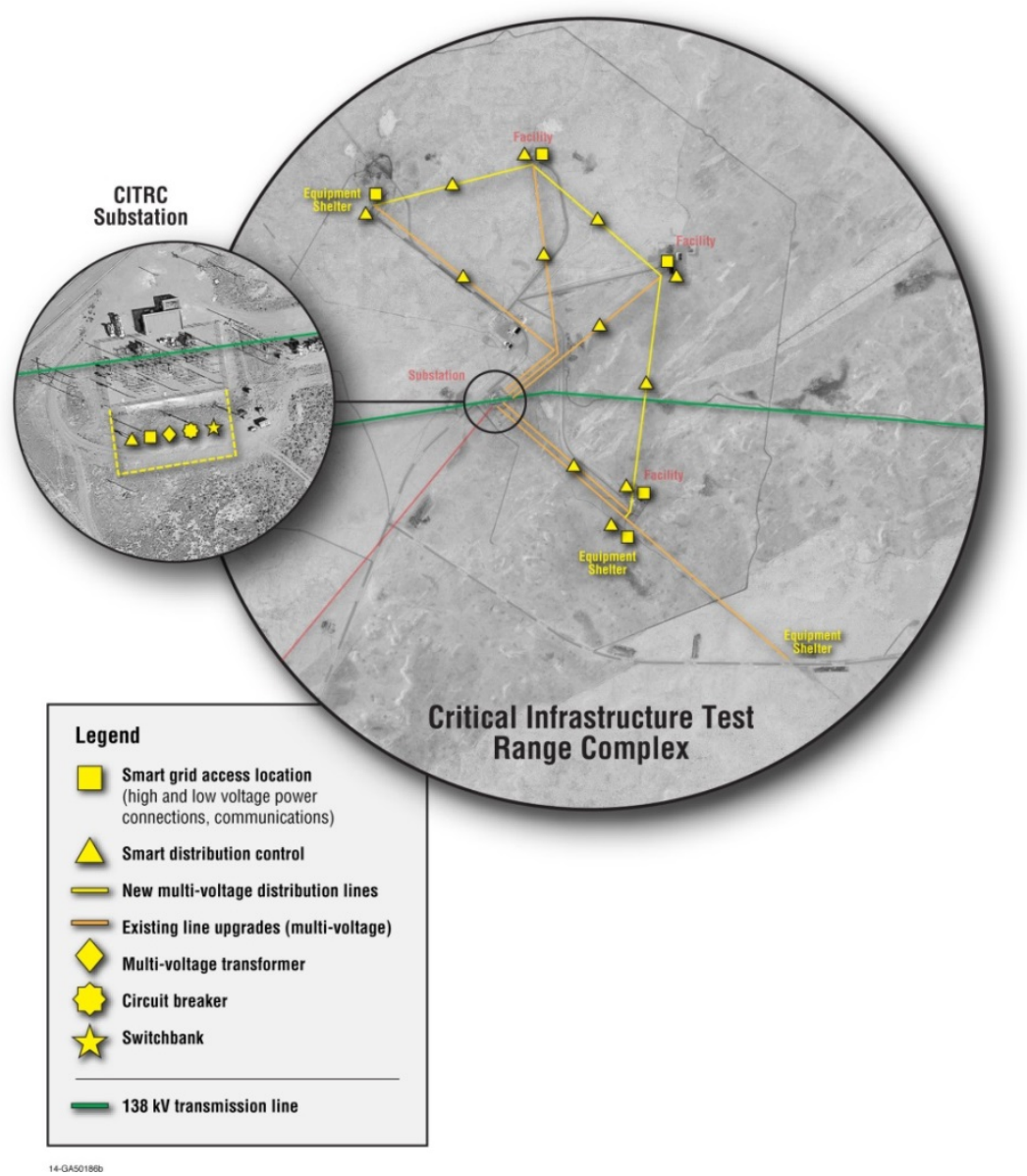

Figure 3. Phase I substation and distribution system enhancement.

- Upgraded CITRC area power grid distribution includes expanding existing radial distribution lines to allow configurable mesh-like operations up to $35-\mathrm{kV}$. New line construction (poles, insulators, lightning arrestors, and wire) will connect the existing radial line ends to enable operation of the lines in both radial and mesh-like configurations. Separate instrumentation and control power will be provided across the new mesh-like network to allow continuous data collection and support power to ancillary equipment operations during test disruptions due to equipment malfunctions, simulated faults, etc.

- New access locations including shelters, communications interfaces, and low and high voltage power connections as needed for complete interconnection of smart-grid distribution equipment, energy systems, and other smart-grid test systems fielded in and around the power grid test bed.

- A smart-grid communications backbone will be installed interconnecting the command center and all test-bed access locations. The communications backbone will include fiber optic/copper cables, junction, and interface boxes installed within the test bed and across the mesh-like network to enable communications for smart devices and equipment. Rack type interfaces will be established at access locations including facilities, line end points, and mid-line locations and at all line-end shelters to provide high and low voltage power switching controls and communications access points for energy related systems as well as smart control and communications devices. A full range of provisions for 
wireless communications will be identified during the Phase I conceptual design and included at a Phase I level as costs and budget allow.

Again, it should be noted that the extent and type of specific enhancements that are included in the actual Phase I construction may change as a result of the trade-off studies, performance optimization, and cost and budget constraints - all of which are identified during the conceptual design process.

\subsubsection{Industry Participation}

INL currently has relationships with several utility and vendor representatives with ongoing smart grid integration and threat analysis efforts. Non-disclosure agreements and cooperative research and development agreements exist with these asset owner partners allowing the safe sharing of configuration specifics. Partners range from large independent system operators, investor-owned utilities to municipalities. INL has initiated discussion with these entities to ensure relevancy of targeted research gaps necessary for smart grid implementation. INL will leverage these relationships to elicit feedback during the conceptual design phase of the project to ensure industry needs are considered.

\subsubsection{Proposed Project Timeline}

The enhancement project will follow the standard design/build phases for a construction project, including project setup, environmental evaluations, conceptual and title design phases, and subcontracting/construction. The expected time-frame for completion of the Phase I portion of the enhancement is $4^{\text {th }}$ quarter FY 2015.

\subsection{Conclusions}

Together, INL and DOE-OE are enhancing the existing INL electrical transmission and distribution infrastructure to expand the types of testing that can be conducted and increase flexibility for testing configurations. This enhanced INL Power Grid Test Bed will enable development and system scale testing of smart-grid-related technologies and smart devices for interoperability, operational performance, reliability, and resiliency at distribution scale at multiple distribution voltage classes.

The enhancement will be achieved in multiple phases, the first focusing on expanded distribution feeder capability to support flexibility for test configurations and operations at multiple distribution voltage classes, specifically $15-\mathrm{kV}, 25-\mathrm{kV}$, and $35-\mathrm{kV}$, representative of $62 \%$ of the nation's overhead prototypical distribution feeders ${ }^{2}$. Enhancements will also include central distribution control and communications to enable test scenario operations, communications, and continuous data collection during even during system disruptions.

The specific features of the enhanced distribution system will be determined through the design process and associated trade-off studies to address performance optimization and budget considerations. The future phases of development will be defined as part of the trade-off studies performed during the Phase I conceptual design process. 